\title{
Space flight-associated neuro-ocular syndrome (SANS)
}

\author{
Andrew G Lee ${ }^{1,2,3,4,5,6} \cdot$ Thomas H Mader $^{7} \cdot$ C Robert Gibson $^{8} \cdot$ Tyson J Brunstetter $^{9} \cdot$ William J Tarver $^{10}$
}

Received: 23 January 2018 / Accepted: 23 January 2018 / Published online: 12 March 2018

(c) The Royal College of Ophthalmologists 2018

\begin{abstract}
Interesting novel and somewhat perplexing physiologic and pathologic neuro-ocular findings have been documented in astronauts during and after long duration space flight (LDSF). These findings collectively have been termed the "space flightassociated neuro-ocular syndrome" (SANS). The National Aeronautics and Space Administration (NASA) in the United States has meticulously and prospectively documented the clinical, ultrasound, optical coherence tomography imaging, and radiographic findings of SANS including unilateral and bilateral optic disc edema, globe flattening, choroidal and retinal folds, hyperopic refractive error shifts, and nerve fiber layer infarcts (i.e., cotton wool spots). NASA and collaborating researchers continue to study SANS in preparation for future manned missions to space, including continued trips to the ISS, a return to the moon, or perhaps new voyages to the asteroid belt, or the planet, Mars.
\end{abstract}

\section{Introduction}

Specific neuro-ocular findings have been documented over the past decade in astronauts during and after long duration space flight (LDSF). This spectrum of novel and unusual neuro-ocular findings has been termed the "space flightassociated neuro-ocular syndrome" (SANS). The National Aeronautics and Space Administration (NASA) has meticulously and prospectively documented the findings of

Andrew G Lee

aglee@ houstonmethodist.org

1 Department of Ophthalmology, Houston Methodist Hospital, Houston, TX, USA

2 Baylor College of Medicine, Houston, TX, USA

3 Departments of Ophthalmology, Neurology, and Neurosurgery, Weill Cornell Medical College, New York, NY, USA

4 Department of Ophthalmology, The University of Texas Medical Branch, Galveston, TX, USA

5 Department of Ophthalmology, The University of Iowa Hospitals and Clinics, Iowa City, IA, USA

6 UT MD Anderson Cancer Center Houston, TX, USA

7 US Army, Cooper Landing, Alaska, USA

8 Coastal Eye Associates, Webster, TX, USA

9 US Navy, NASA Johnson Space Center, Houston, TX, USA

10 Clinical Services, NASA Johnson Space Center, Houston, TX, USA
SANS in astronauts. The clinical findings of SANS include unilateral or bilateral optic disc edema of variable Frisen grades, globe flattening (GF), choroidal and retinal folds, hyperopic refractive error shifts, and nerve fiber layer infarcts (i.e., cotton wool spots). These clinical findings of SANS correlate with interesting structural changes on both ocular and orbital imaging studies. Although magnetic resonance imaging (MRI) is not available on the International Space Station (ISS), terrestrial orbital and cranial MRI and in flight (on ISS) and terrestrial ultrasound studies, as well as ocular optical coherence tomography (OCT), are used routinely [1-3].

In 2011, Mader et al. first described the key clinical and imaging findings in astronauts after long duration space flight on the ISS. Seven astronauts had complete eye examinations before and after their ISS missions, including cycloplegic and/or manifest refractions and fundus photography. Six astronauts had post-mission OCT and orbital/ cranial MRI, and four astronauts had lumbar punctures (LP). Optic disc edema was noted in five, globe flattening in five, choroidal folds in five, nerve fiber layer infarcts in three, nerve fiber layer thickening in six, and decreased near vision (hyperopic shift) in six. Five of these six-affected astronauts experienced a hyperopic shift varying between $+0.50 \mathrm{D}$ to $+1.75 \mathrm{D}$. These five affected cases showed globe flattening (axial shortening) on orbital MRI and orbital ultrasound. Lumbar punctures were performed in four individuals (total $n=5$, as one individual received two LPs). These LPs documented elevated opening pressures (OP) of $22 \mathrm{~cm}$ of water at return +66 days $(\mathrm{R}+66), 21$ at 


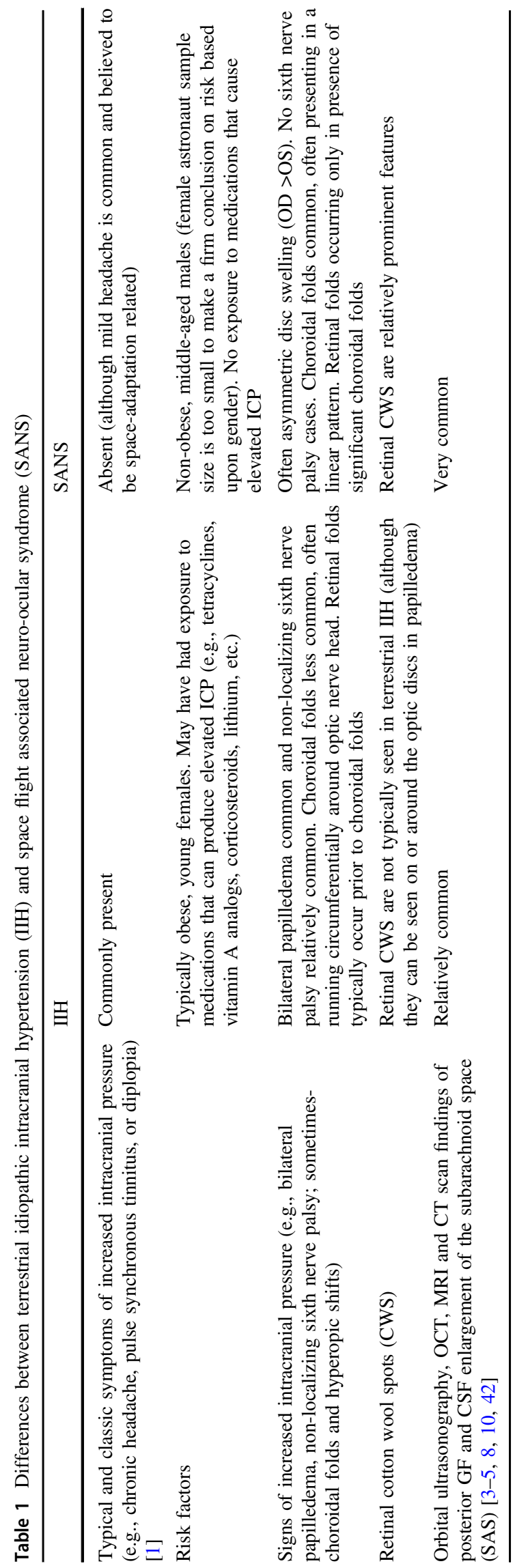

$\mathrm{R}+19,28$ at $\mathrm{R}+12$, and $28.5 \mathrm{~cm} \mathrm{H}_{2} \mathrm{O}$ at $\mathrm{R}+57$. All of these visual changes have been correctable to $20 / 20$ vision, but residual refractive error changes have persisted in some cases for several years after LDSF [1-4].

Idiopathic intracranial hypertension (IIH) has been the closest terrestrial analog to SANS. Table 1 summarizes the differences, however, between IIH on earth and SANS in space [1-12].

Although SANS was initially termed the visual impairment and intracranial pressure (VIIP) syndrome, it remains unclear whether the optic disc edema (variable Frisen scale and often asymmetric) represents true papilledema (i.e., optic disc edema due to increased ICP). In addition, many of the ocular findings are difficult to attribute to elevated ICP (e.g., disproportionate presence of choroidal folds, marked asymmetry or unilaterality, and retinal CWS). In addition, the LP opening pressures to date (albeit performed days to weeks after return to Earth) have been borderline elevated. Compartmentalization of CSF has been proposed [13-16] in terrestrial cases of asymmetric or unilateral papilledema from increased intracranial pressure, and we (AGL) and others (personal communication from Anthony Arnold, MD) have also seen this phenomenon in compressive lesions of the optic canal or the optic nerve sheath (e.g., meningioma). Some authors hypothesize that SANSrelated compartmentalization of CSF within the orbital SAS, with locally elevated sheath pressures rather than elevated ICP alone may help to explain the optic disc edema observed $[1,2,4,5]$.

Since the end of the NASA space shuttle program, astronauts currently use the Russian Soyuz spacecraft for launch to the ISS and return to Earth. The return includes a deceleration of more than $+4.0 \mathrm{G}$ and a hard, parachuteassisted landing in Kazakhstan in the former Union of Soviet Socialist Republics (USSR). Landing in Kazakhstan creates unique political, operational, and logistical barriers to performing an expedited and safe LP in returning astronauts. More rapid and direct transportation to Houston TX, USA currently provides a better window of opportunity for performing LPs after return from the ISS and for measuring true ICP values closer in time to the actual return.

Microgravity studies have documented that cerebral arterial diameter and blood flow velocity are autoregulated and do not change significantly during space flight $[17,18]$. Microgravity fluid shifts have been documented to cause jugular vein distension [19-22] and mild thickening of the retinal nerve fiber layer of the optic nerve (via OCT). These same OCT changes have also been seen in head-down bed rest studies (the terrestrial analog for the cephalad fluid shift in microgravity). The possible role of lymphatics and the venous system in SANS however remains ill defined, but have sparked additional debate and hypotheses [13-16, 2330]. 
OCT, both on ISS and on return to Earth, has demonstrated more widespread than previously believed (based on clinical exams alone) choroidal expansion that may also at least partially account for the hyperopic shift and the choroidal folds. OCT angiography (OCTA), which was not available previously, has demonstrated excellent potential for studying retinal and choroidal disease on Earth and appears promising for the examination of returning astronauts. Additional OCT capability including enhanced depth imaging (EDI) OCT and OCTA might thus be useful in further defining the structural changes seen to date with OCT. The cephalad fluid shift has been hypothesized to produce venous congestion in the neck and head that might lead to elevated vortex vein pressures [31-34] and perhaps decreased choroidal drainage and stagnation or pooling of blood in the choroid. Choroidal expansion has been documented during head-down tilt and transient microgravity studies [31-35]. We anticipate documenting these choroidal volume changes in a more detailed and quantitative manner with newer OCT technology [36-38].

In summary, strange and novel neuro-ocular findings have been documented in astronauts during and after LDSF. The space flight-associated neuro-ocular syndrome (i.e., SANS) is a topic of vigorous debate and some controversy, but remains under intensive prospective study by NASA. Although a single unifying predominant mechanism has yet to be proven $[1,2,4,5,36-41]$ and a multifactorial pathogenesis may still be possible, the cephalad and orbital fluid shifts and the changes in ICP remain the current areas of most concentrated study. Understanding the possible mechanisms for SANS (and potentially developing preventive or counter measures before or during space flight) will be helpful as NASA in the United States and its international partners in space travel prepare for even longer duration space flight missions including return trips to the ISS or the moon, visits to the asteroid belt, or a potential manned mission to Mars.

\section{Disclaimer}

Although the authors have served as employees or consultants for NASA and the contents of this specific manuscript were vetted and reviewed by Lifetime Surveillance of Astronaut Health at the National Aeronautics and Space Administration (NASA), the views and opinions represented here are those of the authors, as well as content already within the public domain, and thus do not necessarily represent the views of the space agency (NASA) or the United States government.

\section{Compliance with ethical standards}

Conflict of interest The authors declare that they have no conflict of interest.

\section{References}

1. Mader TH, Gibson CR, Pass AF, Kramer LA, Lee AG, Fogarty J, et al. Optic disc edema, globe flattening, choroidal folds, and hyperopic shifts observed in astronauts after long-duration space flight. Ophthalmology. 2011;118:2058-69.

2. Lee AG, Tarver WJ, Mader TH, Gibson CR, Hart SF, Otto CA. Neuro-ophthalmology of space flight. J Neuroophthalmol. 2016;36:85-91.

3. Mader TH, Gibson CR, Lee AG. Choroidal folds in astronauts. Invest Ophthalmol Vis Sci. 2016;57:592.

4. Mader TH, Gibson CR, Hart SF, Lee AG. Asymmetric papilledema in idiopathic intracranial hypertension. J Neuroophthalmol. 2016;36:111-2.

5. Mader TH, Gibson CR, Otto CA, Sargsyan AE, Miller NR, Subramanian PS, Hart SF, Lipsky W, Patel NB, Lee AG. Persistent asymmetric optic disc swelling after long-duration space flight: implications for pathogenesis. J Neuroophthalmol. 2017;37:133-39.

6. Sarraf D, Schwartz SD. Bilateral choroidal folds and optic neuropathy: a variant of the crowded disk syndrome? Ophthalmology. 2003;110:1047-52.

7. Sharma M, Volpe NJ, Patel T, Kimmel A. Intracranial hypertension associated with acquired hyperopia and choroidal folds. Retina. 1999;19:260-2.

8. Jacobson DM. Intracranial hypertension and the syndrome of acquired hyperopia with choroidal folds. J Neuroophthalmol. 1995; 15:178-85.

9. Cassidy LM, Sanders MD. Choroidal folds and papilloedema. Br J Ophthalmol. 1999;83:1139-43.

10. Dailey RA, Mills RP, Stimac GK, et al. The natural history and CT appearance of acquired hyperopia with choroidal folds. Ophthalmology. 1986;93:1336-42.

11. Liu D, Kahn M. Measurement and relationship of subarachnoid pressure of the optic nerve to intracranial pressures in fresh cadavers. Am J Ophthalmol. 1993;116:548-56.

12. Tso MO, Hayreh SS. Optic disc edema in raised intracranial pressure. IV. Axoplasmic transport in experimental papilledema. Arch Ophthalmol. 1977;95:1458-62.

13. Killer HE, Jaggi GP, Flammer J, et al. The optic nerve: a new window into cerebrospinal fluid composition? Brain. 2006;129:1027-30.

14. Killer HE, Jaggi GP, Flammer J, et al. Cerebrospinal fluid dynamics between the intracranial and the subarachnoid space of the optic nerve. Is it Always bidirectional? Brain. 2007;130:514-20.

15. Kelman SE, Sergott RC, Cioffi GA, et al. Modified optic nerve decompression in patients with functioning lumboperitoneal shunts and progressive visual loss. Ophthalmology. 1991;98:1449-53.

16. Killer HE, Jaggi GP, Miller NR. Papilledema revisited: is its pathophysiology really understood? Clin Exp Ophthalmol. 2009;37:444-7.

17. Iwasaki K, Levine BD, Zhang R, et al. Human cerebral autoregulation before, during and after spaceflight. J Physiol. 2007;579:799-810.

18. Frey MA, Mader TH, Bagian JP, et al. Cerebral blood velocity and other cardiovascular responses to 2 days of head-down tilt. J Appl Physiol. 1993;74:319-25. 
19. Thornton WE, Hoffler GW, Rummel JA. Anthropometric changes and fluid shifts. In: Johnston R, Dietlein L, editors. Biomedical results from Skylab. Washington, DC: Scientific and Technical Information Office, NASA; 1977. http://lsda.jsc.nasa.gov/books/ skylab//Ch32.htm.

20. Arbeille P, Fomina G, Roumy J, et al. Adaptation of the left heart, cerebral and femoral arteries, and jugular and femoral veins during short- and long-term head-down tilt and space flights. Eur J Appl Physiol. 2001;86:157-68.

21. Harris BA Jr, Billica RD, Bishop SL, et al. Physical examination during space flight. Mayo Clin Proc. 1997;72:301-8.

22. Herault S, Fomina G, Alferova I, et al. Cardiac, arterial and venous adaptation to weightlessness during 6-month MIR spaceflights with and without thigh cuffs (bracelets). Eur J Appl Physiol. 2000;81:384-90.

23. Davson H, Domer FR, Hollingsworth JR. The mechanism of drainage of the cerebrospinal fluid. Brain. 1973;96:329-36.

24. Andersson N, Malm J, Eklund A. Dependency of cerebrospinal fluid outflow resistance on intracranial pressure. J Neurosurg. 2008;109:918-22.

25. Alperin N, Lee SH, Mazda M, et al. Evidence for the importance of extracranial venous flow in patients with idiopathic intracranial hypertension (IIH). Acta Neurochir Suppl. 2005;95:129-32.

26. Kapoor KG, Katz SE, Grzybowski DM, Lubow M. Cerebrospinal fluid outflow: an evolving perspective. Brain Res Bull. 2008;77:327-34.

27. Oreskovic D, Klarica M. The formation of cerebrospinal fluid: nearly a hundred years of interpretations and misinterpretations. Brain Res Rev. 2010;64:241-62.

28. Giuseffi V, Wall M, Siegel PZ, Rojas PB. Symptoms and disease associations in idiopathic intracranial hypertension (pseudotumor cerebri): a case-control study. Neurology. 1991;41:239-44.

29. Johnston M, Zakharov A, Koh L, Armstrong D. Subarachnoid injection of Microfil reveals connections between cerebrospinal fluid and nasal lymphatics in the non-human primate. Neuropathol Appl Neurobiol. 2005;31:632-40.

30. Bershad EM, Urfy MZ, Calvillo E, Tang R, Cajavilca C, Lee AG, et al. Marked olfactory impairment in idiopathic intracranial hypertension. J Neurol Neurosurg Psychiatry. 2014;85:959-64. https://doi.org/10.1136/jnnp-2013-307232. [Epub ahead of print]
31. Mader TH, Taylor GR, Hunter $\mathrm{N}$, et al. Intraocular pressure, retinal vascular, and visual acuity changes during $48 \mathrm{~h}$ of 10 degrees head-down tilt. Aviat Space Environ Med. 1990;61:810-3.

32. Chiquet C, Custaud MA, Le Traon AP, et al. Changes in intraocular pressure during prolonged (7-day) head-down tilt bedrest. J Glaucoma. 2003;12:204-8.

33. Drozdova NT, Grishin EP. State of the visual analyzer during hypokinesia [in Russian]. Kosm Biol Med. 1972;6:46-9.

34. Mader TH, Gibson CR, Caputo M, et al. Intraocular pressure and retinal vascular changes during transient exposure to microgravity. Am J Ophthalmol. 1993;115:347-50.

35. Shinojima A, Iwasaki K, Aoki K, Ogawa Y, Yanagida R, Yuzawa M. Sufoveal choroidal thickness and foveal retinal thickness during head-down tilt. Aviat Space Environ Med. 2012;83:388-393

36. Mader TH, Gibson CR, Otto CA, Sargsyan AE, Miller NR, Subramanian PS, Hart SF, Lipsky W, Patel NB, Lee AG. Why a one-way ticket to Mars may result in one-way directional glymphatic flow to the eye: response. J Neuroophthalmol. 2017;37:463-464.

37. Mader TH, Gibson CR, Lee AG. Optic nerve sheath distention as a protective mechanism against the visual impairment and intracranial pressure syndrome in astronauts. Invest Ophthalmol Vis Sci. 2017;58:4603-4604.

38. Lee AG, Mader TH, Gibson CR, Tarver W. Space flightassociated neuro-ocular syndrome. JAMA Ophthalmol. 2017;135:992-994.

39. Mader TH, Gibson CR, Lee AG, Patel NB, Hart SF, Pettit DR. Unilateral loss of spontaneous venous pulsations in an astronaut. $\mathrm{J}$ Neuroophthalmol. 2015;35:226-7.

40. BR Macias, Liu JH, Grande-Gutierrez N, Hargens AR. Intraocular and intracranial pressures during head-down tilt with lower body negative pressure. Aviat Space Environ Med. 2015;86:3-7.

41. Taibbi G, Ronita L, Cromwell RL, Kapil GK. The effect of microgravity on ocular structures and visual function: a review. Surv Ophthalmol. 2013;58:155-163.

42. Guiffre G, Distefano MG. Optical coherence tomography of chorioretinal and choroidal folds. Acta Ophthalmol Scand. 2007;85:333-6. 